\title{
Implementation of Voltage Optimization for Sustainable Energy
}

\author{
Jian Ding Tan ${ }^{1}$, Siaw Paw Koh ${ }^{2}$, Mau Teng Au ${ }^{3}$, Sieh Kiong Tiong ${ }^{4}$, Kharudin Ali ${ }^{5}$ \\ ${ }^{1,2,3,4}$ Institute of Sustainable Energy (ISE), Universiti Tenaga Nasional, 43000 Kajang, Selangor, Malaysia \\ ${ }^{5}$ Faculty of Electrical and Automation Engineering Technology, TATIUC, Terengganu 24000, Malaysia
}

\begin{tabular}{l}
\hline \hline Article Info \\
\hline Article history: \\
Received May 14, 2018 \\
Revised Jul 1, 2018 \\
Accepted Jul 12, 2018 \\
\hline
\end{tabular}

Keywords:

Voltage Optimization

Low Impedance

Microgeneration

\begin{abstract}
The voltage control in the power distribution network is challenged firstly by constantly increasing in power demand and secondly by a growing number of distributed connections, which significantly changes the load flow in the network. Situation is worsening with the current heavily implemented microgeneration of Solar PV. Consequently, the uncontrollable rapid changes in the power distribution network would affect voltage instability at the feeder with wide area power demand. Voltage instability would affect the energy efficiency of the electrical equipment. Moreover, the lifespan of some equipment would be shortened due to the excessive and unstable voltage supplied. The proposed research aims to implement the low impedance voltage optimization system in solving the existing problem. The voltage optimization system had been tested on both resistive and inductive loads. The power consumption of the loads had been measured at a few discrete values of voltage optimization within the statutory region. Further tests were conducted on industrial water pump, general lightings with mixed loads, office building, restaurant and plastic injection moulding machine. The power measurements were logged and the results in term of power consumption were analysed. The results showed that the proposed optimization mechanism successfully optimize and saved $6.81 \%, 14.42 \%$, $13.97 \%, 12.23 \%$, and $26.23 \%$ of the power consumptions in respective tests.
\end{abstract}

Copyright $@ 2018$ Institute of Advanced Engineering and Science. All rights reserved.

\section{Corresponding Author:}

Jian Ding Tan, Institute of Sustainable Energy (ISE), Universiti Tenaga Nasional, 43000 Kajang, Selangor, Malaysia. Email: jdtan2003@yahoo.com

\section{INTRODUCTION}

In power distribution networks, the adoption of active network management techniques would allow the increase of network ability to accommodate more distribution networks. An active control of the network comprises of continuous monitoring and management of the system voltage in order to be able to undertake proactive actions to ensure the regulatory status of the system [1-3]. The recent uptake of micro-generations of solar PV systems put the distribution system operations in even higher challenges. The outputs from variable renewable energy sources can cause voltage fluctuations, which in turn impact the power quality in distributed-generation systems. The primary issue is on the significant feeder voltage rise. There are also several other factors that cause voltage instability, such as heavily loaded feeders, growing number of connections, and the increment in demands. Several types of voltage controls and regulation systems can be found in the literature, such as on-load tap changers and line voltage regulators. The operating life of the voltage control mechanisms deteriorate due to the non-stop continual operations. For substations, power regulations are carried out through voltage regulators and transformer controls. However, the sliding contacts of the motor-driven-variac are the main causes of the inherent wear and tear problems, and energy loss associated with the design [4-7]. 
Many of our daily electrical devices are designed to operate within a standardized voltage band of \pm $10 \%$ of the nominal $230 \mathrm{~V}$. These are the limits approved in the UK [8]. Efficient operation of these devices requires them to operate at the nominal voltage. The fluctuations from the nominal voltage supply causes a less efficient usage of these devices. Operating these appliances above the required optimum voltage, for instance, does not increase the performance, but instead causes increase in losses, which in turn leads to higher bills and carbon emissions. These losses are usually transformed into heat which contributes to insulation breakdown and shortened the lifespan of the appliance. The quality of the supplied voltage is a major aspect in power quality. A close-to-constant voltage output is essential to ensure the optimum operations of electrical appliances in homes and industries. Literature study shows that the European Union's directive on low voltage stipulates a tolerable range of voltage fluctuations acceptable for normal system operation [9].

Conservation of energy can be achieved through the reduction in the voltage to its nominal. One of the major and direct benefits is the reduction in bills [10]. Several relevant voltage controlling techniques can be found in the literature. Based on the Ferroresonance theorem, a design of Constant Voltage Transformers (CVT) is shown in [11]. A few reports are also found on the advantages of using power electronics over mechanical tap changers in regulating the transformer voltages [12-15]. An AC-AC converter based on the buck-boost topology is reported in [16], which also discussed the advancement of power electronics in power management. A fixed tap changing system in actual applications is reported in [17]. Power electronic tap switching is one of the most commonly applied techniques in this application. Literature study shows that tap changing transformers have been installed at substations to control the fluctuations in voltage levels at the consumer ends. However, this technique usually leads to reduced voltage bands. Voltage optimization devices have also been developed for domestic and industrial applications in order stabilize the voltage level. Voltage optimization is a term most often used to describe the technology used to give an optimal output voltage level for end users. Other terms used to describe this same technology include; Voltage Power Optimization, Supply Voltage Optimization, Conservation Voltage Reduction, Voltage Correction among others. Automatic voltage stabilizers can be grouped into several types, including Electro-mechanical, Ferro resonant (Constant voltage transformer), Electronic step regulators, Saturable reactors and Electronic Voltage Stabilizer [18].

A PV system can only export the power generated back onto the National Grid by increasing the voltage typically by $2 \%$. However the system is not capable to differentiate between the power used in the home or exported back onto the grid. Therefore all generated power is supplied at this higher voltage. As more and more micro-generation is introduced onto the National Grid and supply voltages rise, the energy saving through voltage reduction will become even more beneficial. A voltage optimiser simply supplies a voltage closer to the designed parameters for appliances. Many electrical appliances and electronic devices, such as LEDs are often very sensitive to over voltage. Without proper regulations their operating life can be drastically affected. The generation of renewable energy will be more beneficial to the power system if the energy generated is completely compatible with the electrical loads in the circuit. The installation of voltage optimisation mechanism along with Solar PV systems significantly benefits the customer, not only during non-microgeneration periods of use, but significantly when the generated power from the PV system is used as more of this 'free energy' is available for use around the household. Utilising this normally wasted energy could reduce the payback period on the solar PV installation making them an even more attractive proposition.

\section{AUTONOMOUS DYNAMIC MULTISTAGE INVERSE INDUCTION CONTROL}

In this research, a voltage optimization system is proposed by using autonomous dynamic multistage inverse-induction control connected in-line to the power busbar. This method has low fault impedance with no sliding parts compared to the existing motor-driven-variac technology. It employs power electronics switching algorithm which eliminates the use of sliding contact, which in turn leads to long term reliability. The proposed method brings several other benefits. It minimizes the losses that occur due to having lower impedance, pushes for more fully utilizing equipment ratings, raises power factors and better power quality for the utility and the end-users. The overall system features are described in Table 1.

The proposed system provides immediate automatic and autonomous dynamic voltage control to optimize the input voltage whilst maintaining the output voltage above a user-defined minimum level. The technology is implemented as a voltage management system on low voltage levels. Figure 1 illustrates the connection diagram and the internal block diagram of the system. In the event of control failure on any single control-stage, an automatic bypass control will be activated to disable only the affected control-stage, ensuring that no interruption will be caused to the output of the system. The failure of one control-stage will only affect a particular range of correction voltage while the rest of the control-stages remain unaffected, 
avoiding total failure of the system. The proposed system is able to stabilize and optimize the output voltage supply required by the electrical loads.

Table 1. System Features

\begin{tabular}{|c|c|}
\hline Features & Benefits \\
\hline Active voltage stabilization at $\pm 1 \%$ & Maintains stable voltage even if site voltage fluctuates. \\
\hline Independent 3 phase control & Active phase balancing, improved power quality to enhance equipment life. \\
\hline Solid State Control using zero volt switching & $\begin{array}{l}\text { No moving parts in the power circuits, no annual maintenance required and no } \\
\text { chopping of the waveform. }\end{array}$ \\
\hline $\begin{array}{l}\text { In-built electronic fall-safe mode design with } \\
\text { automatic integral bypass }\end{array}$ & Maintains continuity of supply to site \\
\hline Removal of voltage spikes and surges & Added protection for site equipment and improved power quality \\
\hline Fast Correction Time & $\begin{array}{l}\text { Depending on the application requirement, The system can be configured to attain } \\
\text { its rated output voltage level in not more than } 2 \text { secs responding to the supply } \\
\text { voltage variation. }\end{array}$ \\
\hline $\begin{array}{l}\text { Internal Fault Self-Monitoring and Hold Back } \\
\text { System }\end{array}$ & $\begin{array}{l}\text { Auto-checking any fault of the internal components to avoid any mistake in control } \\
\text { mechanism. }\end{array}$ \\
\hline
\end{tabular}

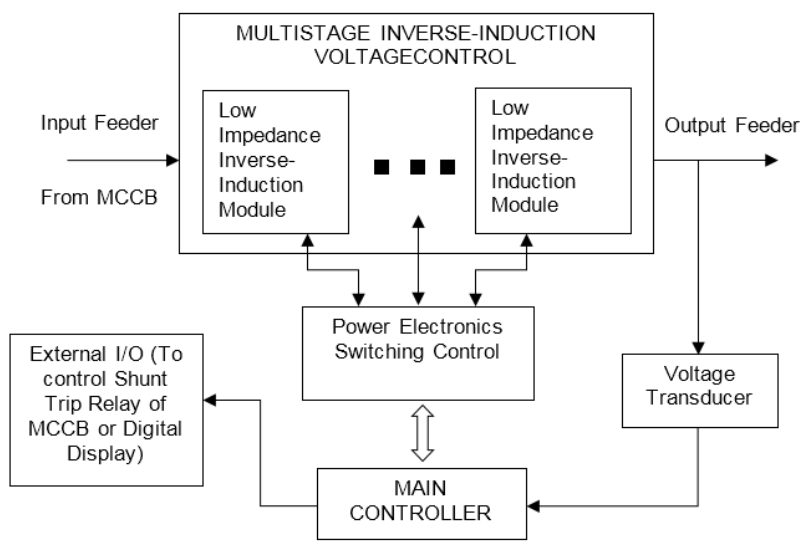

Figure 1. Voltage optimization system block diagram

\section{EXPERIMENTAL RESULTS}

The proposed system is able to provide voltage control to maintain the output voltage at userdefined value. Four discrete values of $220 \mathrm{~V}, 230 \mathrm{~V}, 240 \mathrm{~V}$ and $250 \mathrm{~V}$ have been selected that are within the statutory voltage limit. The proposed system has been tested using both resistive and inductive loads. Both the systems are loaded with electric load of $1.5 \mathrm{~kW}$. The power consumption for the loads at different voltage levels can be observed in Table 2 . The optimization of $30 \mathrm{~V}$ reduction from a reference voltage of $250 \mathrm{~V}$ to $220 \mathrm{~V}$ will give $18 \%-20 \%$ power reduction for resistive load and $9 \%-11 \%$ for medium loaded inductive motor. Besides the impact of a lower voltage level, the significant power reduction is mainly also due to the system advantage of operating in low impedance design and having without the power consuming variac module.

Table 2. Resistive and Inductive Loads Power Consumption at Different Voltage Levels

\begin{tabular}{ccc}
\hline Voltage Level & $\begin{array}{c}\text { Power Deduction for Resistive Loads } \\
\text { (Filaments, } 1.5 \mathrm{~kW})\end{array}$ & $\begin{array}{c}\text { Power Deduction for Inductive Loads (Medium } \\
\text { Loaded Motor, 1.5kW) }\end{array}$ \\
\hline $250 \mathrm{~V}$ & $0 \%$ (reference) & $0 \%$ (reference) \\
$240 \mathrm{~V}$ & $6-8 \%$ & $3-5 \%$ \\
$230 \mathrm{~V}$ & $12-14 \%$ & $6-8 \%$ \\
$220 \mathrm{~V}$ & $18-20 \%$ & $9-11 \%$ \\
\hline
\end{tabular}

Further investigations have been carried out on the applications of the proposed voltage optimization mechanism to improve the energy efficiency in industrial machines and buildings. The power consumption data has been logged before and after the implementation of the proposed voltage optimization mechanism in multiple different cases and applications. 


\subsection{Case 1: Water Pump}

For an initial test, the proposed mechanism is applied to optimize the power consumption of a water pump. A 2 horse power (HP) water pump is used. The data logging was carried out for 5 minutes before the installation of the optimizer and another 5 minutes after its installation to investigate the differences. The data in Figure 2 shows that the average power consumption reduced from $1.835 \mathrm{~kW}$ to $1.710 \mathrm{~kW}$, which translates into a saving of about $6.81 \%$.

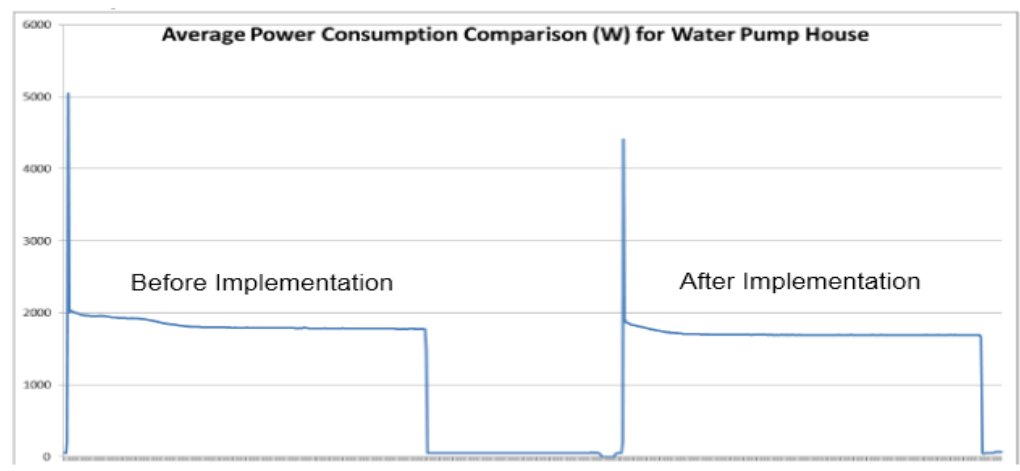

Figure 2. Logged data on the average power consumption for a water pump before and after the implementation of the proposed voltage optimization technique

\subsection{Case 2: Plastic Injection Molding}

In this application, the proposed optimizer is implemented to in a plastic injection molding machine to investigate its performance. The power consumptions before and after the implementation are logged and shown in Figure 3. From the power usage trend, it can be observed that the average power consumption significantly dropped from $9.92 \mathrm{~kW}$ to $8.49 \mathrm{~kW}$, which translates into a $14.42 \%$ saving.

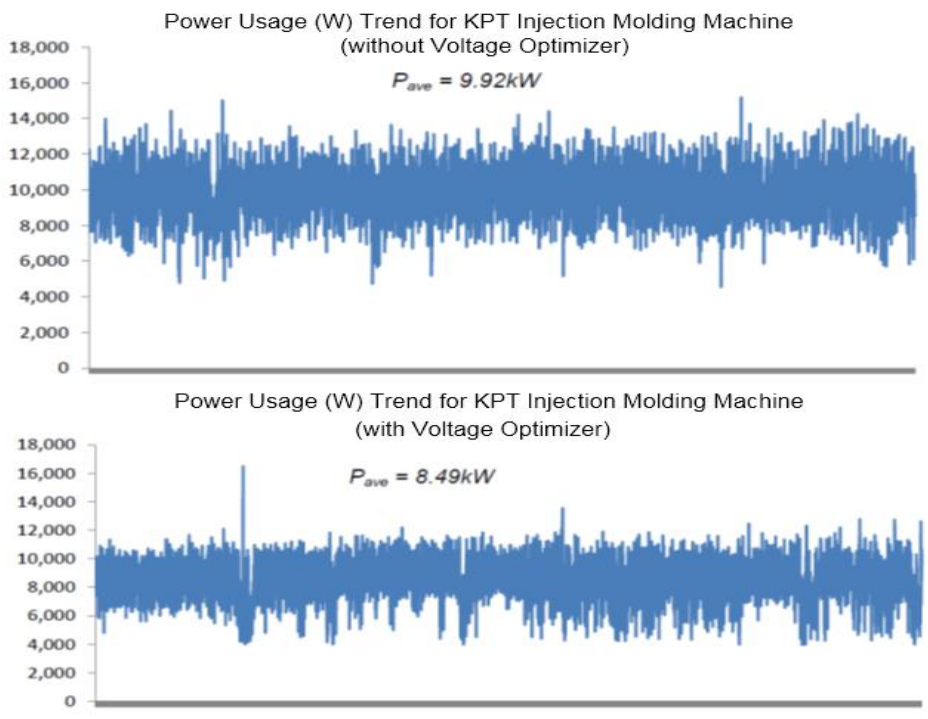

Figure 3. Power usage trend analysis on a plastic injection molding machine before and after the optimizer implementation

\subsection{Case 3: Greenhouse (General Lighting and Mixed Loads)}

The proposed optimizer is tested in a greenhouse with general lightings and mixed loads, such as fans and power plugs. The power consumption was logged for 20 minutes before and another 20 minutes 
after the implementation of the proposed optimizer. The results are shown in Figure 4. It can be observed that the average power consumption reduced from $5.575 \mathrm{~kW}$ to $4.796 \mathrm{~kW}$, which translates to a saving of $13.97 \%$.

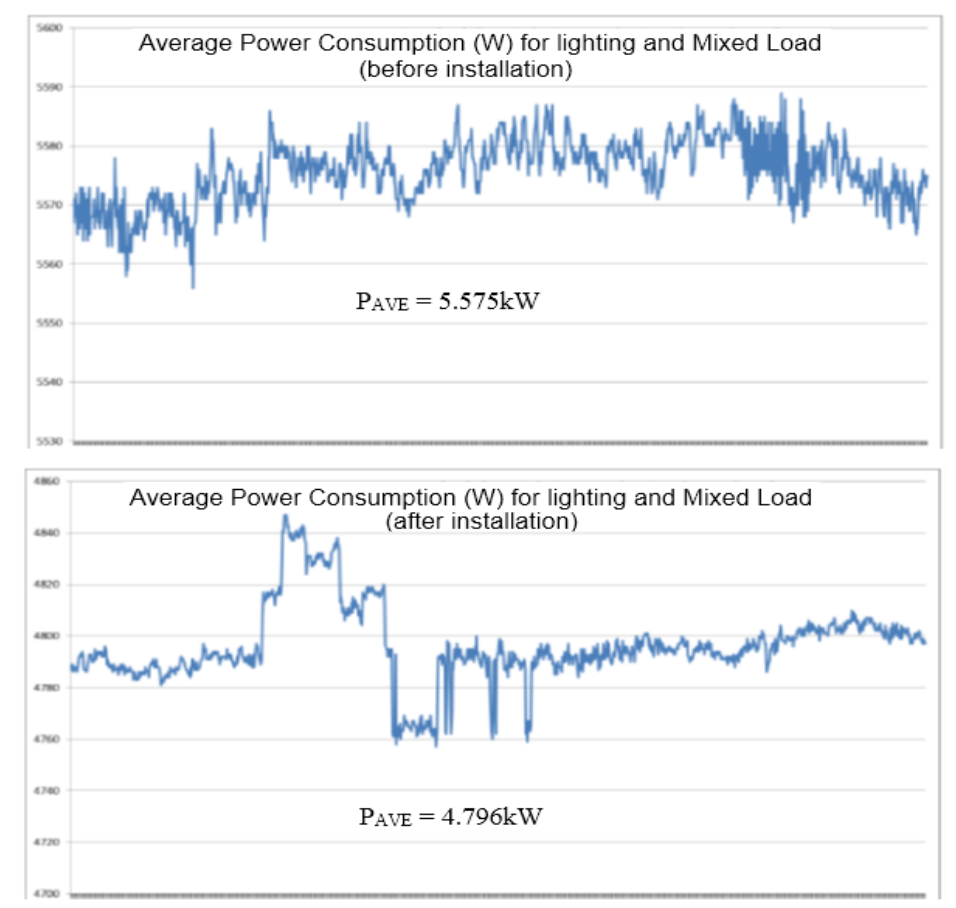

Figure 4. Average power consumption comparison for lighting and mixed-loads in a green house before and after the implementation of the optimizer

\subsection{Case 4: Office Building}

The proposed voltage optimizer is also tested in the power system of an office building. The logged data is shown in Figure 5. In the case of this office building, the saving was found to be at $12.23 \%$. The current (A), apparent power (kVA), and reactive power (kVAR) were found to have reduced by $21.30 \%$, $18.67 \%$, and $32.19 \%$ respectively with the installation of the optimizer.

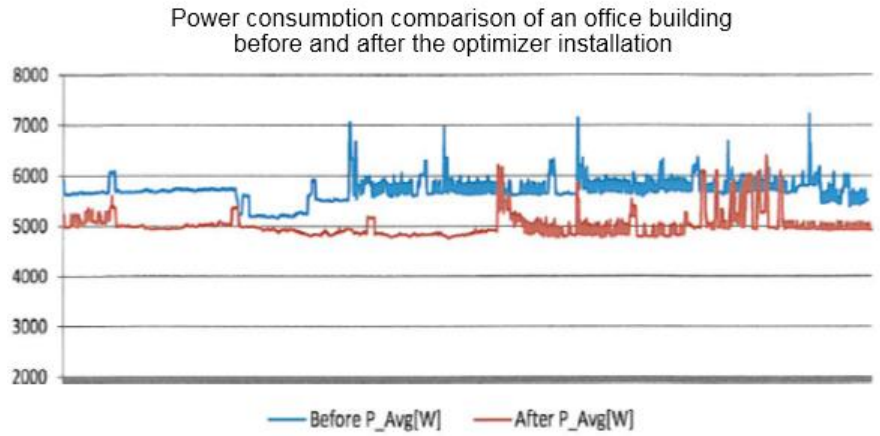

Figure 5. Comparison on the power consumption trend of an office building before and after the implementation of the proposed voltage optimizer

\subsection{Case 5: Restaurant}

For the final case, the proposed voltage optimizer is tested in a restaurant. Testing was performed during evening low peak timing. During the test period, all loads are turned on except the sign-boards and fryer due to the extremely high and unstable current usage. Same loads are used throughout the entire test duration, before and after the installation of the optimizer. The 
logged data is shown in Figure 6. The data shows that the average power consumption dropped from $8604 \mathrm{~W}$ to $6347 \mathrm{~W}$, which translates into a significant power saving of $26.23 \%$.

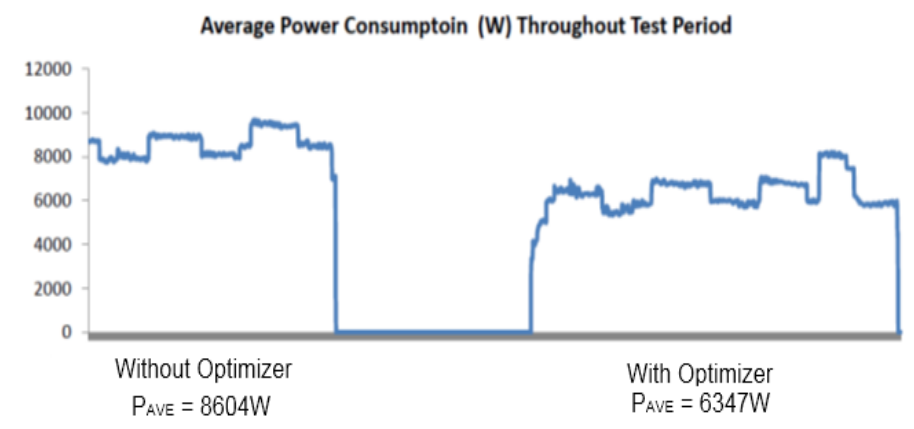

Figure 6. Power consumption comparison before and after the implementation of the voltage optimizer in a restaurant.

\section{CONCLUSION}

Voltage optimisation is one of the most effective methods to achieve energy savings and cost reductions in commercial buildings. In this paper, a voltage optimization system is proposed by using autonomous dynamic multistage inverse-induction control connected in-line to the power busbar. This method grants several advantages compared to that of the conventional method. The proposed voltage optimization mechanism is installed tested for several different applications to investigate its performance under different situations. These applications include a water pump, a plastic injection molding machine, a greenhouse with mixed loads, an office building, and a restaurant. Experiment results showed that the proposed optimization mechanism successfully optimize and saved $6.81 \%, 14.42 \%, 13.97 \%, 12.23 \%$, and $26.23 \%$ of the power consumptions in each of the respective applications. We can thus conclude that the proposed mechanism performs well in optimizing and saving the overall power consumptions. In time to come, we will look into the possibility to further enhance the proposed method and other possible applications.

\section{ACKNOWLEDGEMENTS}

The authors express great acknowledgement to Universiti Tenaga Nasional (UNITEN), Malaysia for the support of this research under the BOLD scheme.

\section{REFERENCES}

[1] Agalgaonkar, Y.P.; Pal, B. C.; Jabr, R. A. "Distribution Voltage Control Considering the Impact of PV Generation on Tap Changers and Autonomous Regulators", Power Systems, IEEE Transactions on Power Systems, pg. 182192, Vol. 29, Issue 1, Jan 2014

[2] Kabiri, R.; Holmes, D. G.; McGrath, B. P. “The Influence of PV Inverter Reactive Power Injection on Grid Voltage Regulation", Power Electronics for Distributed Generation Systems, IEEE $5^{\text {th }}$ International Symposium, pg. 1-8, 2014

[3] Tzung-Lin Lee; Shang-Hung Hu; Yu-Hung Chan “D-STATCOM with Positive-Sequence Admittance and Negative-Sequence Conductance to Mitigate Voltage Fluctuations in High-Level Penetration of DistributedGeneration Systems", IEEE Transactions on Industrial Electronics, pp. 1417-1428, Vol. 60, Issue 4, April 2013

[4] Dozein, M.G.; Ansari, J.; Shahbazi, H. R.; Kalantar, M. "Optimal Distribution Voltage Control Through a SubFramework in the Reactive Power Management on the Smart Grid", Smart Grid Conference, pg 153-159, 2013

[5] Repo, S.; Laaksonen, Hannu; Jarventausta, P.; Huhtala, O.; Meckelsson, M. "A Case Study of a Voltage Rise Problem due to a Large Amount of Distributed Generation on a Weak Distribution Network" Power Tech Conference Proceedings, IEEE Bologna, pg. 6-12, Vol. 4, 2003

[6] "Voltage Management: A Hidden Energy Efficiency Resource," 2013. [Online]. Available: http://www.greentechmedia.com/articles/read/Voltage-Management-A-Hidden-Energy-Efficiency-Resource. [Accessed 23 May 2017].

[7] Masaaki Ishimaru, “ A Study on Voltage Rise Control Effect by Leading Power Factor Operation of PVs Considering Tap Change of Distribution Transformer", Journal of Electrical Engineering in Japan,pp. 46-54, Vol. 180, Issue 3, 2012 


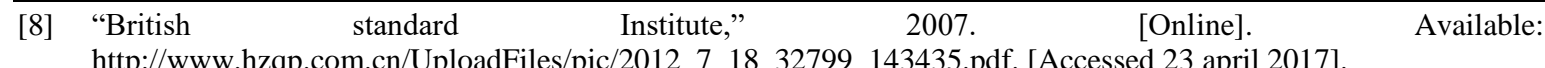

[9] Vazquez, N. Velazquez, A. Hernandez, C., AC Voltage Regulator Based on the AC - AC Buck- Boost Converter, Vigo: IEEE International Symposium on Industrial Electronics vol 533, pp 4-7, 2007.

[10] Sanchez, V. Echavada, R. Cotorogea, M. \&. Claudio, A., Design and Implementation of a Fast On-Load Tap Changing Regulator, Galway: vol 1 pp 488-493, 2000.

[11] Mendis, N. N. R. Yatiyana. E. M. M. B. Wijesingh. K. C. Lucas. J. R. and Perera. R., "Design and Construction of Constant Voltage Transformer," in industrial and information systems, first international conference, Peradeniva (pp 40-45), 2006.

[12] Xiaoming, L. Qingfen. L. Xianggen, Y. \&. Jianghui, X., “A New On-load Tap Changing System with power electronic elements for power transformers," in power system technology, 2002.

[13] An, L. Liu, X. Lu, Q. \&. Yan, J., "Analysis and Design of the Green Voltage Regulator Based on Transformer Coupling," in Intelligent networks and intelligent systems, Tianjin IEEE, 2009.

[14] Zhao Y, Dong, S. Li, J. Yao, X. Zheng, N. and Liu, X, "Study of Non-contact Automatic On-Load Voltage Regulating Distributing Transformer Based on Solid State Relay," in Power electronics and motion control conference (vol 1, pp 1-5), Shangai IPEMC, 2006.

[15] Zhao Y, Dong, S. Zhao, Q. Yue. H.., "Research on Automatic Regulating for Distribution Transformer by Solid State Relays," in Power and Energy Engineering Conference (APPEEC) Vol 1, Issue 4, pp 28-31, Asia-Pacific, 2010.

[16] Vazquez, N. Velazquez, A. Hernandez, C., AC Voltage Regulator Based on the AC - AC Buck- Boost Converter, Vigo: IEEE International Symposium on Industrial Electronics vol 533, pp 4-7, 2007.

[17] “Power Perfector," Power Perfector, 2013. [Online]. Available: http://www.powerperfector.com/. [Accessed 20 April 2017].

[18] Pyone, Y.Y, "Design of Transformers for 60kVA Automatic Voltage Stabilizer," in Computer and Automation Engineering, Bangkok vol 318, no 322 pp 8-10, 2009. 